原著

\title{
出血で発症した末梢性後下小脳動脈瘤への外科的治療戦略
}

\author{
中村 道夫, 和泉 允基, 宮崎 格, 篠崎 夏樹
}

\section{Surgical Strategies for Ruptured Distal Posterior Inferior Cerebellar Artery Aneurysms}

\author{
Michio Nakamura, M.D., Ph.D., Masaki Izumi, M.D., Tadashi MiYazaki, M.D., and \\ Natsuki SHINOZAKI, M.D., Ph.D.
}

Department of Neurosurgery, Narita Red Cross Hospital, Narita, Chiba, Japan

\begin{abstract}
Summary: To identify the best surgical strategies, we analyzed our experience with distal posterior inferior cerebellar artery aneurysms (distal PICA AN) and reviewed the literature. We treated 6 patients with ruptured distal PICA ANs. The ANs were located at the anterior medullary segment (AMs: 2 cases), lateral medullary segment (LMs: 2 cases), televelotonsillar segment (TTs: 1 case), and cortical segment (Cs: 1 case). The AN at the Cs was a feeder aneurysm of a cerebellar arteriovenous malformation (AVM). All patients underwent direct surgery. Prior to surgery, 3 ANs were diagnosed as saccular type, and the remaining 3 were considered fusiform types, based on digital subtraction angiography or computed tomography angiography. However, one case of fusiform type appeared saccular during intraoperative observation. Neck clipping for saccular type ANs and trapping combined with occipital artery-PICA bypass for fusiform type ANs were successfully performed. Sparing of perforating branches adjacent to the ANs was attempted as much as possible during the trapping procedure. A transcondylar fossa approach was selected for the proximal segment (AMs, LMs) of the distal PICA ANs to decrease the risk of lower cranial nerve palsies. Standard lateral suboccipital craniotomy for a TTs AN and midline suboccipital craniotomy for a Cs AN were performed. All patients recovered favorably without ischemic complications or lower cranial nerve palsies. Preparation for revascularization with bypass, preservation of the perforators, and approaches using skull base techniques enable a good surgical result for distal PICA ANs.
\end{abstract}

\section{はじめに}

椎骨動脈 (vertebral artery：VA)-後下小脳動脈 (posterior inferior cerebellar artery：PICA) 分岐部以降に発生する 末梢性後下小脳動脈瘤 (distal PICA aneurysm : distal PICA AN) は全脳動脈瘤の $1.0 \%$ 未満の頻度とされ ${ }^{8) 10) 16) 18), ~ ま れ ~}$ な疾患である。加えて, PICAの近位部からは脳幹穿通枝

\author{
Key words: \\ - distal posterior inferior \\ cerebellar artery \\ aneurysm \\ - occipital artery-posterior \\ inferior cerebellar \\ artery bypass \\ - saccular aneurysm \\ - fusiform aneurysm \\ - transcondylar fossa \\ approach
}

Surg Cereb Stroke

(Jpn) 45: 464-470, 2017

成田赤十字病院 脳神経外科(受稿日 2017. 3. 4) (脱稿日 2017. 6. 9) 〔連絡先： ₹ 286-8523 千葉県成田市飯田町 90-1 成田赤十字病院 脳 神経外科 中村道夫] [Address correspondence: Michio Nakamura, M.D., Ph.D., Department of Neurosurgery, Narita Red Cross Hospital, 90-1 Iida-cho, Narita, Chiba 286-8523, Japan] 
Table 1 Clinical summary of 6 patients with ruptured distal PICA aneurysms

\begin{tabular}{|c|c|c|c|c|c|c|c|c|c|c|c|}
\hline $\begin{array}{l}\text { Case } \\
\text { No. }\end{array}$ & $\begin{array}{l}\text { Age/ } \\
\text { sex }\end{array}$ & $\begin{array}{l}\text { WFNS } \\
\text { grade }\end{array}$ & $\begin{array}{c}\text { Location } \\
\text { of AN }\end{array}$ & Type of AN & $\begin{array}{c}\text { Timing of } \\
\text { surgery/day }\end{array}$ & Approach & $\begin{array}{l}\text { Surgical } \\
\text { method }\end{array}$ & $\begin{array}{c}\text { Surgical } \\
\text { complication }\end{array}$ & $\begin{array}{l}\text { Additional } \\
\text { treatment }\end{array}$ & $\begin{array}{l}\text { Bypass } \\
\text { patency }\end{array}$ & $\begin{array}{c}\mathrm{mRS} \text { at } 3 \\
\text { months }\end{array}$ \\
\hline 1 & $71 / F$ & $4 \rightarrow 3$ & AMs & Fusiform & 3 & $\begin{array}{c}\text { Transcondylar } \\
\text { fossa }\end{array}$ & $\begin{array}{c}\text { Trapping } \\
\text { OA-PICA } \\
\text { bypass }\end{array}$ & $\begin{array}{l}\text { Wound } \\
\text { necrosis }\end{array}$ & Shunt & Good & 2 \\
\hline 2 & $54 / F$ & 2 & AMs & Saccular & 1 & $\begin{array}{c}\text { Transcondylar } \\
\text { fossa }\end{array}$ & $\begin{array}{c}\text { Neck } \\
\text { clipping }\end{array}$ & No & No & NP & 0 \\
\hline 3 & $45 / F$ & $5 \rightarrow 3$ & LMs & Fusiform & 21 & $\begin{array}{c}\text { Transcondylar } \\
\text { fossa }\end{array}$ & $\begin{array}{c}\text { Trapping } \\
\text { OA-PICA } \\
\text { bypass }\end{array}$ & No & Shunt & Good & 2 \\
\hline 4 & 77/F & 3 & LMs & $\begin{array}{c}\text { Fusiform } \rightarrow \\
\text { Saccular }\end{array}$ & 1 & $\begin{array}{c}\text { Transcondylar } \\
\text { fossa }\end{array}$ & $\begin{array}{c}\text { Neck } \\
\text { clipping }\end{array}$ & No & No & NP & 0 \\
\hline 5 & $49 / F$ & $3 \rightarrow 1$ & TTs & Saccular & 14 & $\begin{array}{c}\text { Lateral } \\
\text { suboccipital }\end{array}$ & $\begin{array}{c}\text { Neck } \\
\text { clipping }\end{array}$ & No & No & NP & 0 \\
\hline 6 & $54 / F$ & $2 \rightarrow 1$ & Cs & $\begin{array}{c}\text { Saccular } \\
\text { (AVM } \\
\text { feeder) }\end{array}$ & 30 & $\begin{array}{c}\text { Midline } \\
\text { suboccipital }\end{array}$ & $\begin{array}{l}\text { Neck clipping } \\
\text { AVM removal }\end{array}$ & No & No & NP & 1 \\
\hline
\end{tabular}

AN: aneurysm, AMs: anterior medullary segment, LMs: lateral medullary segment, TTs: televelotonsillar segment, Cs: cortical segment, OA-PICA bypass: occipital artery-posterior inferior cerebellar artery bypass, AVM: arteriovenous malformation, NP: not performed, WFNS: World Federation of Neurological Surgeons, mRS: modified Rankin Scale

PICA およびその穿通枝を可能なかぎり温存する方針で, 血行再建を含めた直達手術で distal PICA AN の治療を 行っている. 当院での治療結果と文献的な考察から, distal PICA AN を安全に治療するための外科的治療戦略を検 討したので報告する.

\section{対象と方法}

2001 年 1 月から 2016 年 12 月までに, 当施設において 根治的な治療を行った破裂脳動脈瘤 557 症例のうち, distal PICA AN は 6 例 (1.1\%)であった. 年齢は 45-77 歳(平 均 58.3 歳), 全例が女性であった。動脈瘤の部位は, PICA を5つの segmentに分けた Lister ${ }^{12)}$ の分類に準じる と, anterior medullary segment (AMs) 2 例, lateral medullary segment(LMs) 2 例, televelomedullary segment (TMs) 0 例, televelotonsillar segment(TTs) 1 例, cortical segment $(\mathrm{Cs}) 1$ 例であった. Cs の 1 例は, 小脳虫部の脳 動静脈奇形 (arteriovenous malformation: AVM)の feeder aneurysmで, 動脈瘤が出血源であった，術前の digital subtraction angiography(DSA)，または computed tomography angiography (CTA)で, saccular type と診断したの は AMs 1 例, TTs 1 例, Cs 1 例の計 3 例で, AMs 1 例と LMs 2 例の計 3 例は fusiform type と考えられた，全例に 直達手術を行った，原則として急性期手術で臨んだが，2 週間以降の待機手術が 3 例存在した。 その内訳は, 来院時 の神経学的重症例〔World Federation of Neurological Surgeons (WFNS) grade 5] が 1 例, 小脳 AVM 合併例で動脈 瘤の処置と AVM 同時摘出を計画した症例が 1 例, CT 上
で脳腫脹が疑われた 1 例であった，AMs，LMs の動脈瘤 に対して transcondylar fossa approach を，TTsの動脈瘤 に対して lateral suboccipital craniotomyを, Cs の動脈瘤 に対して midline suboccipital craniotomy を選択した。 ま た，fusiform type が疑われた 3 例には，開頭時に occipital $\operatorname{artery}(\mathrm{OA})$-PICA bypass を想定し，血行再建の準備 を行った(Table 1).

\section{結果}

術前検查で fusiform type が疑われた 3 例のうち, AMs の 1 例と LMsの 1 例は trapping および OA-PICA bypass を行ったＬLMsの 1 例では fusiform type を想定して手術 に臨んだが，術中所見で saccular type であることが確認 され, neck clippingを行った. 術前検査で saccular type と診断した 3 例 (AMs，TTs，Cs 各 1 例)に neck clipping が可能で，そのうち Cs の 1 例では clipping と小脳 AVM の全摘出を行った。術後の DSA または CTA で全例に動 脈瘤の消失を確認し，血行再建を行った 2 例では OA-PICA bypass の開存と PICA 末梢の血流温存を確認した. 下位脳神経麻疩を含めた手術による神経症状の悪化例はな く, 3 カ月後の mRS は 0-2であった (Table 1).

\section{症例}

〈症例 1：Case 1〉71 歳, 女性.

意識障害で発症し，day 1 に転院搬送された。来院時 Glasgow Coma Scale(GCS)は E2 V2 M4, WFNS grade 4, $\mathrm{CT}$ で後頭蓋窩に多いくも膜下出血 (subarachnoid hemor- 

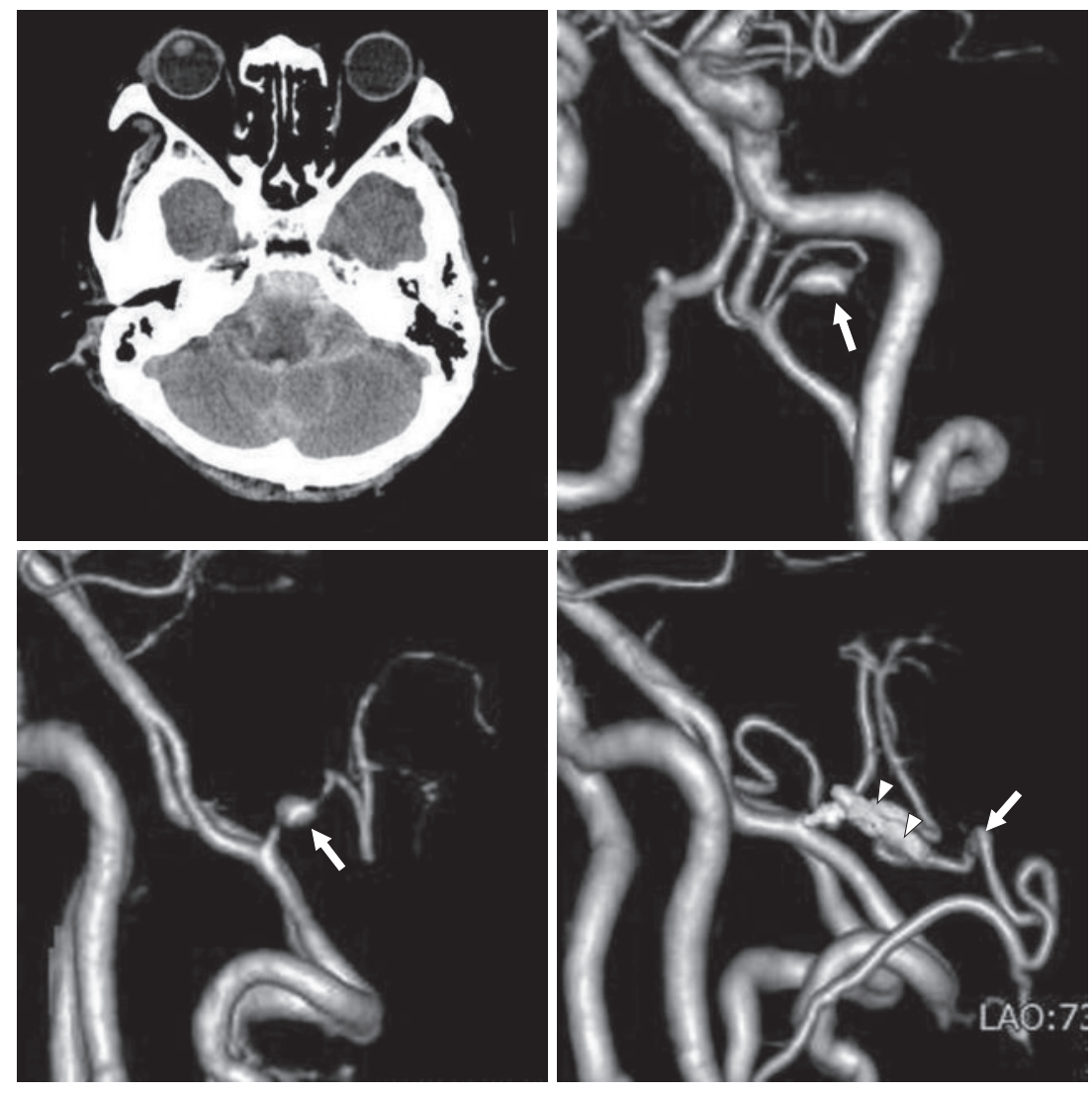

\section{\begin{tabular}{c|c} 
A & B \\
\hline C & D
\end{tabular}}

Fig. 1 Computed tomography (CT) and CT angiography (CTA) in Case 1.

A: CT on admission, revealing a dense subarachnoid hemorrhage (SAH) in the posterior fossa.

B, C: CTA on admission, showing a fusiform aneurysm (AN: arrow) at the anterior medullary segment (AMs) of the left posterior inferior cerebellar artery (PICA).

D: Postoperative CTA demonstrates disappearance of the fusiform AN and good patency of the occipital artery (OA)-PICA bypass (arrow).

Arrowheads represent both proximal and distal clips.

rhage：SAH）と急性水頭症を認めた(Fig. 1A)。CTAにて 左 PICAのAMsに発生した fusiform type AN と診断し た(Fig. 1B，C). 同日, 脳室外ドレナージを行い, 意識レ ベルが GCS E3 V4 M6 まで改善したため, day 3 に手術を 行った. hockey stick incision で皮切を行い OA 確保し たうえで, transcondylar fossa approachを行った. 動脈 瘤周囲の血餅を除去し, PICA の近位部と遠位部を露出し た．動脈瘤はDSAの所見通り neckをもたない fusiform type であったため, まず PICA の caudal loop へ OA-PICA bypass を行い, 引き続き動脈瘤の trapping を行った(Fig. 2A). trapping 後に動脈瘤の全周を観察すると, 動脈瘤の 近位側に脳幹穿通枝が認められ trapping に含まれてい た. distal clipの手前で動脈瘤を切断して domeに可動性 をつけると，近位側の PICA と穿通枝の分岐部がよく確認 された. domeを PICA 側にわずかに残すように proximal clip をかけ直して, 穿通枝を温存した(Fig. 2B，C). 術中 indocyanine green (ICG) 蛍光造影にて穿通枝の温存を確認 した。術後の 3D CTA で動脈瘤の消失, OA-PICA bypass の開存, PICA 末梢の血流温存を確認した(Fig. 1D).

〈症例 4 : Case 4〉77 歳, 女性.

頭痛とめまいで発症し，救急搬送された，来院時 GCS
E3 V4 M6, WFNS grade 2, CT で第 4 脳室内出血を認め た(Fig. 3A)。 DSA およびCTAでは, 左 PICA の LMsに 動脈瘤を認め(Fig. 3B，C), 分枝のない本幹部にあること と形状から fusiform type AN と診断した. day 1 に OA を確保したうえで, transcondylar fossa approachで手術 を行った.下位脳神経の腹側に接してPICAの AMs, LMs が走行し, 迷走神経に付着した血餅を除去すると LMs の急峻な curve のわずか遠位に動脈瘤が認められた (Fig. 3D). 分枝する血管は認めなかったが，しっかりと した neckが確認できたため saccular type と判断して OA-PICA bypass は行わず, neck clipping を行った(Fig. 3E)。術後 CTA にて動脈瘤の消失を確認した(Fig. 3F).

\section{考察}

distal PICA ANの特徴として, 解離を含むfusiform type の頻度が高く, Lehto ら $^{8}$ の報告では出血発症の 58 例中, 26 例 (45\%)が fusiform type であったとしている. VA-PICA 分岐部以降のどの部位にも発生し, 特に走行上 の屈曲の強い部位に多( ${ }^{25}$ )16). 血管の分岐部によらず発 生し得ることや (2)516), AVMの合併例が多いこと年16) など から, 発生のメカニズムに hemodynamic stress が関与す るとされる ${ }^{217)}$ ，治療においては直達手術，血管内手術の 

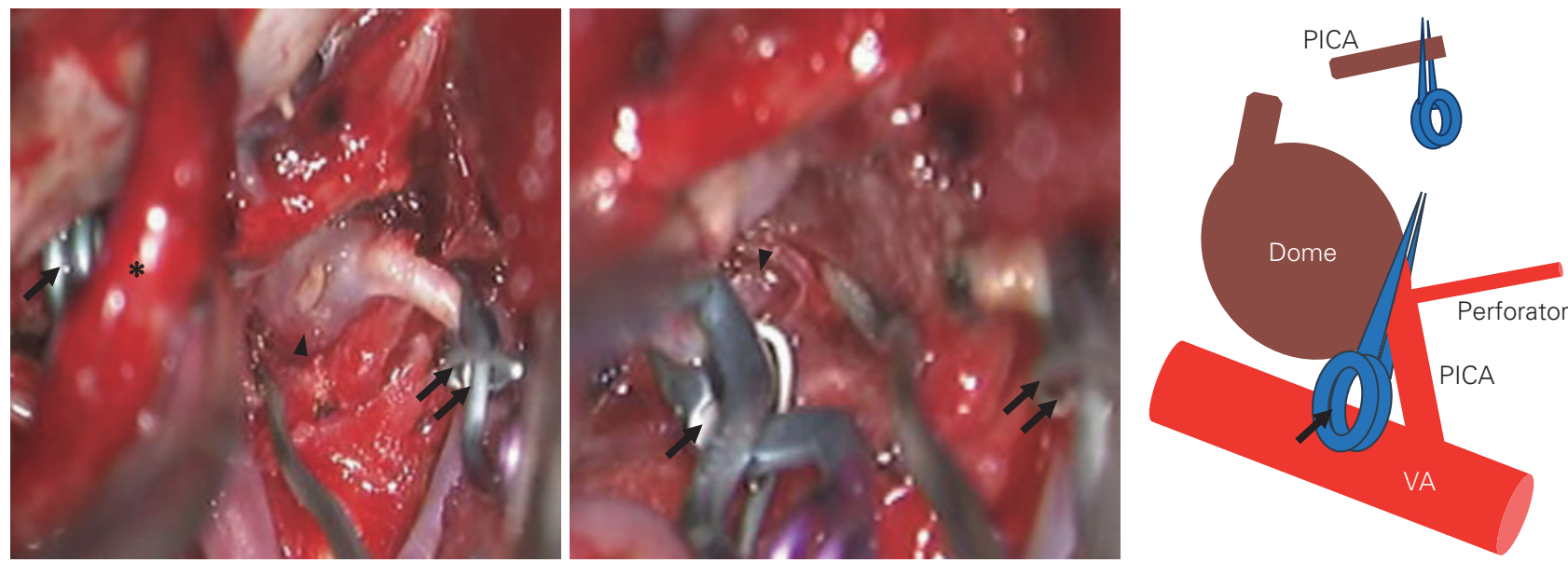

Fig. 2 Intraoperative photographs $(\mathbf{A}, \mathbf{B})$ and schematic drawing $(\mathbf{C})$ in Case 1.

A $|\mathbf{B}| \mathbf{C}$

A: Following occipital artery (OA)-posterior inferior cerebellar artery (PICA) bypass at the caudal loop of the PICA, the aneurysm (AN) was trapped with two Sugita aneurysm clips. An arrow and double arrows represent proximal and distal clips, respectively. Arrowhead represents the AN. Asterisk represents OA.

B: A brainstem perforator was preserved by repositioning the proximal clip to the dome after the distal end of the AN was resected from the PICA to mobilize the dome. Arrow represents repositioned proximal clip, and double arrows represent distal clip. Arrowhead represents the perforator from the proximal PICA.

C: Schematic drawing of Case 1 demonstrating that the proximal clip (arrow) was applied to the dome obliquely to preserve the perforator.

どちらも行われる部位だが，その選択にはいまだに議論が 多( ${ }^{822)}$ 。直達手術では, fusiform type に対して動脈瘤の trappingに血行再建を併用する報告が多( ${ }^{19) 1318) 21)}$ 。 ま た, 根治性については不明な点もあるが, wrappingや wrap on clip による治療報告例もある ${ }^{5) 6(19) 24)}$. 近年では, この部位の動脈瘤に対しても coil 塞栓術による治療の報告 が多くなっている ${ }^{3) 41122)}$. しかし, coil 塞栓術では saccular type であっても, PICAの屈曲蛇行や, 血管径の細さ から PICAの温存が困難な例もあり, fusiform type では PICA の閉塞が前提となる ${ }^{34111)}$. PICA はその前半部分に

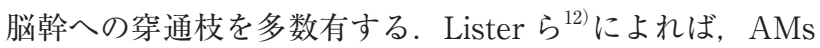
から 0-2 本, LMs から 0-5 本, TMs から 0-11 本存在し, PICA 近位部での閉塞で起こり得る脳虚血は小脳半球だけ でなく，延髄脳幹に及ぶ可能性もある．PICAの血流支配 領域は, 同側の前下小脳動脈, 上小脳動脈, 対側の PICA から複雑な側副血行を受ける. PICA を閉塞しても, 虚血

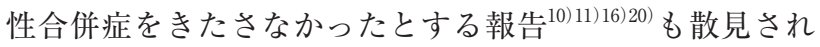
るが, 側副血行の程度や, 特に脳幹穿通枝領域の血行動態 を術前に予測することは困難と考えられる ${ }^{12) 13) 21)}$. 水谷 ${ }^{15)}$ はVA 解離性動脈瘤 (PICA-involved type)の直達術におい て，血行再建を行わずPICA を閉塞した 8 症例中 4 例に小 脳梗塞が発生したと報告した。 また, Chalouhi ら ${ }^{3)} も ， 76$ 例の PICA ANの血管内治療において, PICAの温存が不
可能であった 11 例中 6 例 $(54.5 \%)$ に梗塞性合併症を認め たとしている。Petr ら ${ }^{22)}$ は, 文献上の meta-analysisの結 果から, distal PICA AN に対する血管内治療は, PICA 前半部だけでなく，脳幹穿通枝の関与の少ない TMs 以降 の治療においても，母血管閉塞による虚血性合併症が直達 手術よりも有意に高かったとしている。これらの報告を踏 まえると, AMs-TMsの distal PICA ANの治療には, PICA 末梢の血流温存と脳幹穿通枝の温存が必須と考えら れる。 また，穿通枝の関与のないTTs 以降の distal PICA $\mathrm{AN}$ でも，母血管の安易な閉塞は避けるべきであり，血管 内治療では選択的 balloon test occlusion (BTO) で, 直達手 術では PICA の一時遮断後の ICG 蛍光造影などで側副血 行の評価を行い, 閉塞の可否を判断すべきであろう.われ われは，直達手術によって直視下に動脈瘤の性状を観察す ることで, clipping か trappingのどちらが適切かを判断 し, trappingに際しては血行再建によるPICA 末梢の血 流を確保し，同時に穿通枝を極力温存する方針をとってい る. 症例 1(Case 1) では AMs の fusiform type AN の trappingに際し，あえてわずかに dome 近位部を残存させる ように proximal clip を移動させて, 脳幹穿通枝を順行性 の血流によって温存した.このような clip workは, dome と正常血管の境界付近から分枝する穿通枝を温存す るためには有効と考える。乙供ら ${ }^{21)}$ は distal PICA ANの 

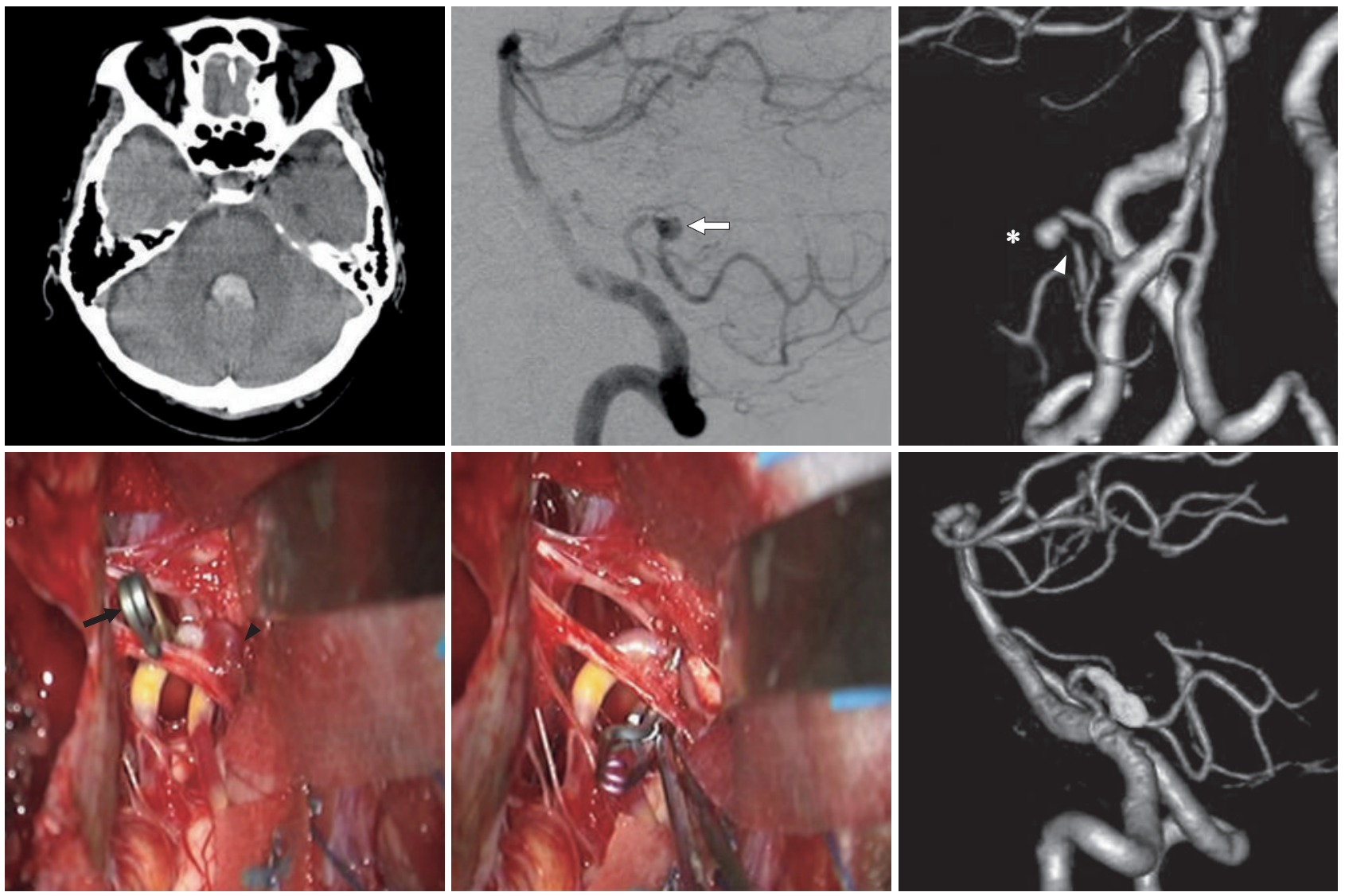

Fig. 3 Computed tomography (CT), digital subtraction angiography (DSA), CT angiography (CTA), and in\begin{tabular}{l|l|l} 
A & $\mathbf{B}$ & $\mathbf{C}$ \\
\hline $\mathbf{D}$ & $\mathbf{E}$ & $\mathbf{F}$
\end{tabular} traoperative photographs in Case 4.

A: CT on admission, revealing intraventricular hemorrhage exclusively in the fourth ventricle.

B: Lateral view of the left vertebral DSA on admission, showing an aneurysm (AN: arrow) at the lateral medullary segment (LMs) of the left posterior inferior cerebellar artery (PICA).

C: Right oblique view of CTA demonstrating aneurysmal dilatation at the non-branching portion (asterisk) as well as narrowing of PICA (arrowhead) just distal to the AN. Those findings suggest that the AN might be a fusiform type or a dissection.

D: Intraoperative photographs, showing that the AN (arrowhead) is located just distal to the hairpin curve at the LMs. Although the AN is located at the non-branching portion of the PICA, the neck of the AN is clearly shown, indicating as a saccular type AN. Note that a transcondylar fossa approach provides a wide working space with minimum retraction of the cerebellum. Arrow represents a temporary clip.

E: The AN was successfully clipped without compromising the flow in the PICA.

F: Postoperative CTA, demonstrating disappearance of the AN and good patency of the PICA.

trappingにおいて, trapping 遠位からの bypass 血流は distal clip の末梢から分枝する穿通枝の血流をも温存でき るとしている，穿通枝が終末動脈となる以上，長期的な開 存は不明であるが, 周術期の脳幹梗塞予防の意味から重要 と考える.

今回経験した症例 4(Case 4) では, 術前の画像所見で動 脈瘤の存在部位が血管分枝によらず，また neckも明らか でなかったため fusiform type と診断した。手術では OAPICA bypass 準備して臨んだが, 術中所見から saccular type であることが判明し neck clippingに変更した. 前述
のように, distal PICA AN は saccular type でも動脈の分 枝部位に関連なく, PICA の屈曲部に発生することが多い ため ${ }^{25) 16)}$ ，血管撮影所見から saccular か fusiform かを治 療前に診断することが困難な症例も存在する ${ }^{16)}$. このよう な症例では, 直視下での動脈瘤の確認が PICA 温存の観点 からもきわめて重要と考えられた.

distal PICA AN の直達手術において, 最も頻度の高い 合併症に下位脳神経麻瘴が挙げられる ${ }^{1 / 8) 9(22)}$. 特に PICA 前半部 AMs, LMs の動脈瘤では, 手術操作による下位脳 神経への直接的な損傷の他に, 小脳の牽引による機械的な 
損傷も起こり得る.われわれは, 小脳の外側への牽引を極 力減じるために, transcondylar fossa approach を選択し た。その結果, 通常の lateral suboccipital approach より も側方視野の展開が開け, 最低限の杽引で広い working space を得ることができた，松島ら ${ }^{14)}$ は，大後頭孔外側部 の手術において, 病変の存在部位や高さによって transcondylar fossa approach, transcondylar approach, lateral suboccipital craniotomyを使い分けることを提唱し, 特に 延髄, 椎骨動脈を斜め横から見上げる形となる transcondylar fossa approach がVA-PICA 分岐部動脈瘤に最も適 しているとしている. 頚静脈結節を顆窩から舌下神経管に 向かい深く骨削除するが, 環椎後頭関節面を削除しない 分, transcondylar approachに比べて簡便であり, 術後の 頚部可動制限などの合併症も少ない ${ }^{14)}$. この approach を 選択した症例は, AMs, LMs の 4 例で, うち 3 例は急性 期での手術であったが, 術後の下位脳神経麻瘏を認めな かった. 同様の報告として, Todaka ${ }^{23)}$ は transcondylar fossa approachにより, Liew ら ${ }^{10)}$ は far lateral transcondylar approachにより, AMs, LMsの動脈瘤に下位脳神 経麻痺の合併なく手術が可能であったとしている.

最後に，この手術で用いられる血行再建について述べ る.われわれが選択したOA-PICA bypassは, distal PICA AN の直達術に限らず, PICA involved type の VA 解離, VA の大型動脈瘤の治療に扔いても汎用性が高 (13)15) 18)21). 同様の目的で PICA-PICA side to side anastomosis, radial artery(RA) や superficial temporal artery (STA)を graft としたVA-RA (STA)-PICA bypass, 動脈 瘤切除後の PICA end to end anastomosis などが報告され ている ${ }^{1779)}$. このうち PICA-PICA side to side anastomosis は OA を皮弁から剝離する手間が省けるだけではな く, 術後の皮弁の血流不全, $\mathrm{OA}$ の硬膜入口部からの髄液 漏などの OA-PICA bypass 特有の合併症がないため推奨 する報告例が多( ${ }^{177)}$. しかし, PICA の左右径が極端な場 合や片側が欠損する症例があること ${ }^{1)}$ ， PICAの走行には 解剖学的な variation が多いこと ${ }^{12}$ などから, 手技自体の 遂行が困難な症例もあるため, 術前の血管撮影所見を参考 に, 症例によって OA-PICA bypass と使い分けることが 必要と考えられる。

\section{ま と め}

distal PICA AN の根治的治療において, fusiform type では, 虚血性合併症を避けるために血行再建を併用した直 達手術が有効である. trappingに際しては, 動脈瘤の近 傍から分枝する脳幹穿通枝の温存に極力努力する必要があ

る.また，術前の画像診断からは fusiform type か saccular type かの判断が困難な例も存在し, PICA 温存の意味
からも直視下での動脈瘤の観察による clipping, trapping の判断が必要である。下位脳神経麻痺を含む合併症回避の 観点からは, transcondylar fossa approach などの頭蓋底 技術を併用した手術 approach が，特に急性期手術におい て必要と考えられた。

\section{文献}

1) Abla $\mathrm{AA}$, McDougall $\mathrm{CM}$, Breshears JD, et al: Intracranial-tointracranial bypass for posterior inferior cerebellar aneurysms: options, technical challenges, and results in 35 patients. J Neurosurg 124: 1275-1286, 2016

2）姉川繁敬，林 隆士，鳥越隆一郎，ほか：破裂末梢性後下小 脳動脈瘤一自験例 13 例 14 個の分析. No Shinkei Geka 29: 121-129, 2001

3) Chalouhi N, Jabbour P, Starke RM, et al: Endovascular treatment of proximal and distal posterior inferior cerebellar artery aneurysms. J Neurosurg 118: 991-999, 2013

4) Crowley RW, Albuquerque FC, Ducruet AF, et al: Technical consideration in the endovascular management of aneurysms of the posterior inferior cerebellar artery. Neurosurgery 71 (2 Suppl): ons 204-217, 2012

5) Horiuchi T, Tanaka Y, Hongo K, et al: Characteristics of distal posterior inferior cerebellar artery aneurysms. Neurosurgery 53: 589-596, 2003

6) Jafar JJ, Kamiryo T, Chiles BW, et al: A dissecting aneurysm of the posteroinferior cerebellar artery: case report. Neurosurgery 43: 353-356, 1998

7) Kakino S, Ogasawara K, Kubo Y, et al: Treatment of vertebral artery aneurysms with posterior inferior cerebellar arteryposterior inferior cerebellar artery anastomosis combined with parent artery occlusion. Surg Neurol 61: 185-189, 2004

8) Lehto H, Harati A, Niemelä M, et al: Distal posterior inferior cerebellar artery aneurysms: clinical features and outcome of 80 patients. World Neurosurgery 82: 702-713, 2014

9) Lewis SB, Chang DJ, Peace DA, et al: Distal posterior inferior cerebellar artery aneurysms: clinical features and management. J Neurosurg 97: 756-766, 2002

10) Liew D, Ng PY, Ng I: Surgical management of ruptured and unruptured symptomatic posterior inferior cerebellar artery aneurysms. Br J Neurosurg 18: 608-612, 2004

11) Lim SM, Choi IS, Hum BA, et al: Dissecting aneurysms of the distal posterior inferior cerebellar arteries: clinical presentation and management. AJNR Am J Neuroradiol 31: 11181122, 2010

12) Lister JR, Rhoton AL Jr, Matsushima T, et al: Microsurgical anatomy of the posterior inferior cerebellar artery. Neurosurgery 10: 170-199, 1982

13）松田俊憲, 井川房夫, 大林直彦, ほか：後下小脳動脈 anterior medullary segment に発生した破裂脳動脈瘤の 2 手術症例 一穿通枝温存と後下小脳動脈の虚血について. No Shinkei Geka 32: 867-874, 2004

14）松島俊夫, 福井仁士 : 大後頭孔外側部からのアプローチ：主 として顆窩経由法(別名 後頭顆上部頚静脈結節経由法) と後 頭顆経由法. No Shinkei Geka 24: 119-124, 1996

15）水谷 徹 : 解離性脳動脈瘤に対する手術適応と術式. 脳卒中 の外科 30: 424-428, 2002

16）西野昌子, 桜井芳明, 佐藤博雄, ほか：末梢性後下小脳動脈 瘤(Distal PICA Aneurysm) 一自験 10 例からの検討. No Shinkei Geka 19: 925-932, 1991 
17) Nishizaki T, Tamaki N, Nishida Y, et al: Aneurysms of the distal posterior inferior cerebellar artery: experience with three cases and review of the literature. Neurosurgery 16: 829-832, 1985

18) Nussbaum ES, Mendez A, Camarata P, et al: Surgical management of fusiform aneurysms of the peripheral posteroinferior cerebellar artery. Neurosurgery 53: 831-834, 2003

19) Nussbaum ES, Madison MT, Myers ME, et al: Dissecting aneurysms of the posterior inferior cerebellar artery: retrospective evaluation of management and extended follow-up review in 6 patients. $J$ Neurosurg 109: 23-27, 2008

20) Orakcioglu B, Schuknecht B, Otani N, et al: Distal posterior inferior cerebellar artery aneurysms: clinical characteristics and surgical management. Acta Neurochir(Wien) 147: 11311139, 2005
21）乙供大樹, 川島明次, 川口浩司, ほか：PICA 原発の紡錘状 動脈瘤に対し血行再建術を併用し治療が奏功した 4 例. No Shinkei Geka 40: 331-336, 2012

22) Petr O, Sejkorová A, Bradáč O, et al: Safety and efficacy of treatment strategies for posterior inferior cerebellar artery aneurysms: a systematic review and meta-analysis. Acta Neurochir (Wien) 158: 2415-2428, 2016

23) Todaka T, Hamada J, Yano S, et al: Successful clipping of a distal posterior inferior cerebellar artery aneurysm located on the anterior surface of the medulla oblongata-case report. Neurol Med Chir (Tokyo) 42, 158-161, 2002

24) Yamaura A, Isobe $\mathrm{K}$, Karasudani $\mathrm{H}$, et al: Dissecting aneurysms of the posterior inferior cerebral artery. Neurosurgery 28: 894-898, 1991 